DOI: $10.21105 /$ joss.00660

\section{Software}

- Review ¿

- Repository ca

- Archive ${ }^{\top}$

Submitted: 14 March 2018

Published: 04 May 2018

\section{Licence}

Authors of papers retain copyright and release the work under a Creative Commons Attribution 4.0 lnternational License (CC-BY).

\title{
Mapelia and friends: create 3D models from maps
}

\section{Amelia Ortiz-Gil ${ }^{1}$ and Jordi Burguet-Castell ${ }^{2}$}

1 University of Valencia, Valencia, Spain 2 None

\section{Summary}

This software was created to help with the development of 3D models of planets, moons and so on, used in the non-profit project A Touch of The Universe (group 2018) on educational astronomy.

There are several programs related to images of maps and 3D files:

- mapelia - convert maps into 3D figures with reliefs.

- guapelia - optional GUI to use mapelia.

- pintelia - convert maps into colored 3D figures.

- poligoniza - form faces (polygons) from 3D points.

- stl-split - split a 3D globe into the north and south hemispheres.

The input images are jpg or png files that contain maps (that is, gridded datasets where the value of each pixel is the elevation) in any of several possible projections (equirectangular, Mercator, central cylindrical, Mollweide or sinusoidal).

The output of the programs are 3D files (of polygons like ply or stl, or points in space like asc), that can be visualized and manipulated with programs like MeshLab or Blender.

In the project $A$ Touch of The Universe, the generated stl files are directly printed with a $3 \mathrm{D}$ printer, to create a physical representation of diverse planets and moons. Those printed models are then used to do outreach in astronomy at the Aula del Cel (The Sky Classroom) (cel 2018) in the Astronomical Observatory of the University of Valencia among other places.

\section{Maps}

- Finding and Using Space Image Data

- Planetary Data System

\section{Projections}

- equirectangular

- Mercator

- central cylindrical

- Mollweide

- sinusoidal

\section{Formats}

- ply

- stl

- asc 


\section{Processing}

- Pillow

- NumPy

- Meshlab

- Blender

\section{References}

cel, Aula del. 2018. "Aula Del Cel (the Sky Classroom)." 2018. http://aorgil.blogs.uv. es/aula-del-cel/.

group, Astrokit. 2018. "Astrokit." 2018. https://astrokit.uv.es/. 